\title{
REDUPLICATION IN KANASHI
}

\author{
Satarupa Dattamajumdar \\ The Asiatic Society, Kolkata
}

\begin{abstract}
Kanashi, a Tibeto-Burman language is spoken in the Malana district of Himachal Pradesh in India. The present discussion concentrates on a particular grammatical phenomenon known as 'reduplication'. By definition the concept of Reduplication stands for repetition or copying of a word or a syllable either exactly or with partial change in the phonological or morphological structure and the copied part is affixed to the base element in order to bring some modification in the semantic interpretation of the base element or to convey some special meaning. (Dattamajumdar, 2001:3). This study of reduplication is a part of the grammatical study of the Kanashi language which is an ongoing work. The data of the present work has been collected from Kanashi mother tongue speaker, an inhabitant of Malana district of Himachal Pradesh. The data has been collected and presented here using International Phonetic Alphabet.
\end{abstract}

\section{INTRODUCTION}

Kanashi is the language spoken in the Malana district of Himachal Pradesh. Genealogically, Kanashi is identified as a Tibeto-Burman language of Sino-Tibetan language family. The language has been classified as a Kinauri language belonging to West-Himalayish group of Tibeto-Kanauri branch of Tibeto-Burman group. It is said to be related with Milchang, a subbranch of Kinnauri group of languages. That Kanashi language is an admixture of Sanskrit and Tibetan varieties has been stated by Bangroo and Stronski(2002). The language has been observed to have no intelligibility with the neighboring languages spoken in Lahul-Spiti and Kinnaur. The language has been referred to as a definitely endangered by UNESCO. According to http://archive.ethnologue.com the speaker strength of Kanashi is 1,400.

\section{THE CONCEPT OF REDUPLICATION}

Reduplication is a grammatical feature found in the modern Indian languages. By definition the concept of Reduplication stands for repetition or copying of a word or a syllable either exactly or with partial change in the phonological or morphological structure and the copied part is affixed to the 
base element in order to bring some modification in the semantic interpretation of the base element or to convey some special meaning. (Dattamajumdar, 2001:3).

\section{OBJECTIVE OF THE STUDY}

Abbi(1992) claims the phenomenon of reduplication as an areal feature not only of the languages of the Indian sub continent but also of the SouthAsian languages. The present discussion which concentrates on a particular grammatical phenomenon known as 'reduplication' is a part of the grammatical study of the Kanashi language which is an ongoing work. The data of the present work has been collected from Kanashi mother tongue speaker, an inhabitant of Malana district of Himachal Pradesh. The data has been collected and presented here using International Phonetic Alphabet.

\section{REDUPLICATED STRUCTURES IN KANASHI}

As observed in Kanashi, reduplicated structures may belong to the category of full reduplication as well as partial reduplication. Fully reduplicated forms refer to those structures which are formed by exact doubling of the base form without any phonological alteration in the copied affixed part of the structure. On the other hand partially reduplicated forms refer to those structures which involve alteration in the phonological shape of the affixed copied part of the reduplicated structure. Fully reduplicated structures can be of two types- fully reduplicated words and fully reduplicated expressives.

Fully reduplicated structures can be formed by reduplicating the words or lexical items of the language and by reduplicating expressive (that are imitation of natural sounds or expressive of senses).

Partially reduplicated structures can be formed from word or lexical items as well as from expressive (that are imitation of natural sounds or expressive of senses) by means of partial phonological alteration in the affixed copied part. Partially reduplicated expressive can be formed by:

i. Insertion of a vowel in the final position of the prefixed copied part

ii. Replacement of a consonant in the initial position of the suffixed copied part

iii. Insertion of a vowel in the final position of the suffixed copied part

The types of reduplicated structures as realized in the Kanashi language is presented in the following table. 
Table-1: Formal classification of Reduplicated structures as realized in the Kanashi language

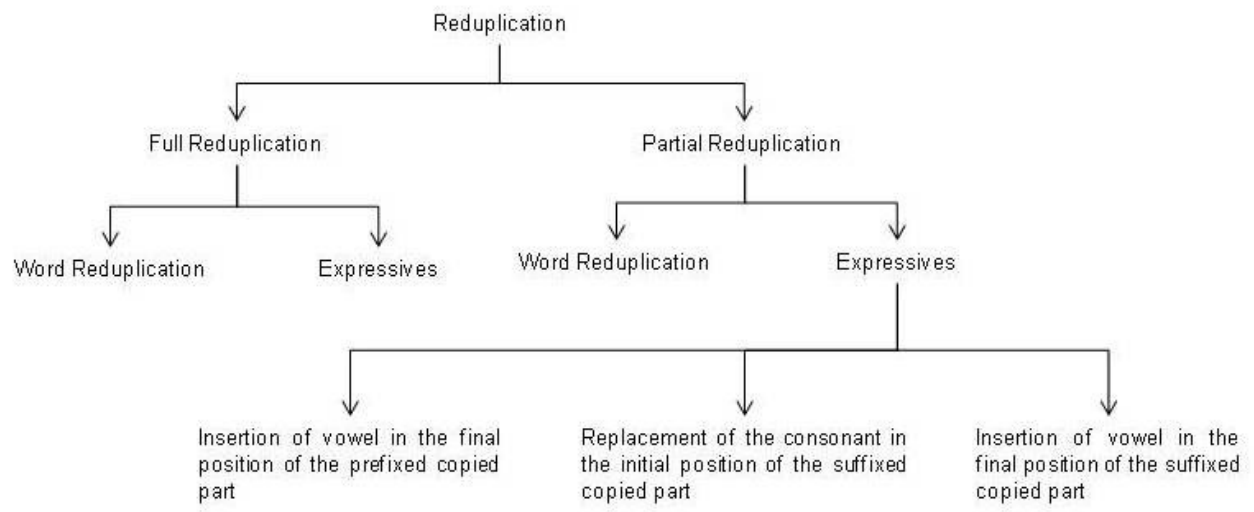

The reduplicated structures may involve semantic modifications or may also be employed to convey the meaning of some peculiar expressions of senses or feelings. The semantic modifications which are involved in the reduplicated structures can be realized only when compared with the meanings of the non-reduplicated counterparts or base elements. These are morphologically and semantically distinct structures of a language having unique characteristics of their own. Being an important structural phenomenon of the South Asian languages reduplicated structures play a vital role in the system of communication and so demands a vivid description of its form and function with reference to the semantic interpretation.

\section{FULL REDUPLICATION}

\section{Word Reduplication}

The words or the lexical items belonging to different word classes are found to be reduplicated in order to bring modification in the semantic interpretation. This is what is known as word reduplication. Kanashi attests reduplicated nouns, pronouns, verbs, modifiers (both nominal and verbal), whereas reduplicated conjunctions and postpositions are not available.

\section{Reduplicated nouns}

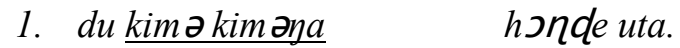

he house-pl. house-pl.-loc. walk-conj. be- $3^{\text {rd }}$ pr. sg.

'He goes to each and every house.' 
2. rindza rindzona $d^{h}$ onefi ut 2 . sister-pl. sister-pl.-with talk-conj. be-pr.cont. $3^{\text {rd }} \mathrm{pl}$. '(Only) the sisters are talking.

\section{Reduplicated Pronouns}

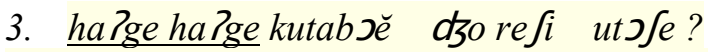

what what book-pl.-det. here sell-conj. be-pr. ${ }^{\text {rd }} \mathrm{pl}$. -inter.

'What(pl.) are the books being sold(/selling) here?'

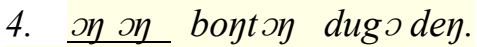

those those go-fut. $1^{\text {st }}$ pl. they go-fut.pf. $2^{\text {nd }}$ pl.(imp.)

'Those who will (wish) to go they (will) go.'/ 'Those who want to go they will go.'

\section{Reduplicated Nominal Modifiers}

5. dus $p^{h} a$ Tke $p^{h} a$ The ttis $\supset$ lobige uta. she-ag. small-pl. small-pl. thing-acc. like-conj. be-pr. $3^{\text {rd }}$ sg.

'She likes small small thing(s).'

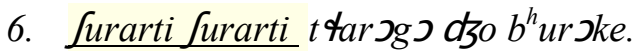
naughty naughty child-pl. here come-pr.pf. $3^{\text {rd }} \mathrm{pl}$.

'(Only) naughty children have come here.'

\section{Reduplicated Verbs}

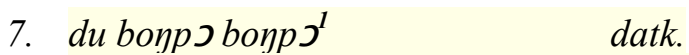
he go-impf. parti. go-impf.parti. fall-past $3^{\text {rd }} \mathrm{sg}$.

'He fell while going'.

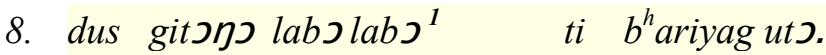
he-ag. song-pl. sing-impf.parti. impf.parti. water fill-pr.cont. $3^{\text {rd }} \mathrm{sg}$.

'While singing he was filling the water.' 
9. mot 4 spthubJttubJ uerigek.

fish-acc. catch- impf.parti. catch- impf.parti. evening be-past $3^{\text {rd }} \mathrm{sg}$.

'It became evening while catching fish.'

Reduplicated Verbal Modifiers

10. iske iskes mગtकp mo godzu utग.

someone someone -ag. fish-acc. neg.eat be-pr. $3^{\text {rd }} \mathrm{pl}$.

'Some people do not eat fish.'

11. roz roz dukJ kay swasi ut J.

everyday everyday he-gen. body bad be-pr. $3^{\text {rd }} \mathrm{sg}$.

'Each and every day his body remains unwell (sick).

\section{Expressives (Fully Reduplicated)}

Kanashi attests a number of fully reduplicated expressives. These may be imitation of natural sounds or may be expressive of senses. The fully reduplicated expressives are both phonologically and semantically significant in the language.

Some examples are given in the following.

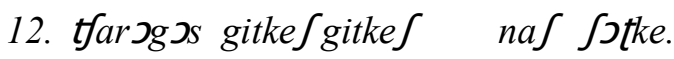
child-pl. expr. of jumping spoil do-pr.pf. $3^{\text {rd }} \mathrm{pl}$.

'The children hampered (the peace) by making the sound of jumping.'

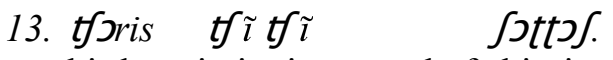

bird-ag. imitative sound of chirping do-pr.cont. $3^{\text {rd }} \mathrm{pl}$.

'The birds are chirping (with the sound).'

\section{PARTIAL REDUPLICATION}

\section{Word Reduplication}

Partially reduplicated words or lexical items in Kanashi involve deletion of the final consonant in the prefixed copied part. Examples are given below. 
14. po tog sp sobuds ra ran we fige. fruit-pl. all-to having given repeatedly finish-past pf. $3^{\text {rd }} \mathrm{pl}$. 'Having given repeatedly to all, the fruits have finished.'

\section{5. kuli la lad kim sanmek. laborer having engaged repeatedly house build-past $3^{\text {rd }} \mathrm{sg}$. 'Engaging the laborer repeatedly the house was built.'}

\section{Expressives (Partially Reduplicated)}

Partially reduplicated expressives which involve a partial phonological alteration in the affixed copied part is prevalent in Kanashi. Alteration of a vowel or a consonant in the affixed copied part has been observed in case of the partially reduplicated structures in Kanashi. Depending upon the phonological alteration, partially reduplicated expressives can be of three types-

I. Insertion of vowel in the final position of the prefixed copied part

II. Replacement of the consonant in the initial position of the suffixed copied part

III. Insertion of vowel in the final position of the suffixed copied part

Such partially reduplicated expressives are exemplified below.

i. Insertion of vowel in the final position of the prefixed copied part

16. $t \int \tilde{a} g \supset \operatorname{deg} d \mathrm{~d}$ ubre utग.

tea imitative sound of boiling boil-pr.cont. $3^{\text {rd }} \mathrm{sg}$.

'The tea is boiling with the boiling sound.'

17. putfus $k^{h}$ गndup krotekrt zaut .

mouse-ag. sugar-acc. imitative sound of biting eat-pr.cont. $3^{\text {rd }} . \mathrm{sg}$.

'The mouse is eating the sugar by making the sound of biting.'

ii. Replacement of the consonant in the initial position of the suffixed copied part

It is to be noted that such reduplicated expressive can take the suffix -e to form nominal modifiers. 
18. teloz zrbore utว.

oil imitative sound of smoking/burning be-pr. cont. $3^{\text {rd }} \mathrm{sg}$.

'The oil is smoking with the sound'.

19. putfus grex Sott?.

rat-ag. imitative sound of rapid movement do- pr.cont. $3^{\text {rd }} \mathrm{sg}$.

'The rat is moving by making the sound.'

iii. Insertion of vowel in the final position of the suffixed copied

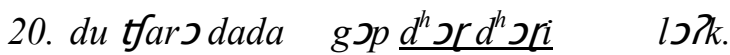

det. child having fall lot expr. of panting of heart seem-past pf. $1^{\text {st }}$ sg.

' The fall of the child I ( my heart) started panting a lot.'

21. ands was $t^{h} u r t^{h} u r i$ lo?k.

me-acc. hunger expr. of hunger seem-past pf. $1^{\text {st }} \mathrm{sg}$.

'I am feeling extremely hungry out of hunger.'

Apart from above discussed reduplicated structures Kanashi attests a peculiar structure used for the imitative sound of thundering. This particular form does not fully conform to the definition of reduplication but only a syllable in the medial position is found to be reduplicated. The example is cited below.

21. sərgગna gururugə rotke.

sky-loc. imitative sound of thundering be-pr.pf. $3^{\text {rd }} \mathrm{pl}$.

'It is thundering (with the sound) in the sky.'

\section{SEMANTIC INTERPRETATION OF THE REDUPLICATED STRUCTURES}

The identified semantic features of the reduplicated structures as realized in the Kanashi language are- Distributive plurality, Exclusiveness, Degree of 
Manifestation, Simultaneity of action and Repetition. Each of the semantic features is discussed below.

1. Distributive Plurality

Reduplicated structures are often found to be employed in order to express plurality and distributiveness of a form. This is a widely and very commonly used semantic interpretation of the reduplicated structures. The above examples number- 1, 3, 5and 11 convey the semantic feature - distributive plurality.

2. Exclusiveness

The semantic feature exclusiveness refers to the interpretation of the reduplicated structures which are employed to convey the sense of 'only' or something 'particular'. Examples number 2, 4, 6 and 10 (mentioned above) convey this semantic feature.

3. Degree of Manifestation

Reduplication is often used in order to mean different degrees or measures of some feelings, emotions, senses, state, process and actions. The different degrees of the senses like 'hesitation', 'mildness', 'excellence', 'similarity', 'immediacy', 'intensity', 'incompleteness', 'certainty' are conveyed by the reduplicated structures. Examples number 12, 20, 21 and 22 convey the semantic feature-degree of manifestation.

4. Simultaneity of Action

This is a semantic feature which involves two events or actions taking place at the same time. This has been referred by Abbi (1992) as an aspectual category. Simultaneity of action involves synchronization of two events or actions in terms of the completion of the events together or protraction of one of the action or continuity of two events along a span of time. Abbi (1992: 32) rightly points out that though this sense of simultaneity can be expressed by temporal phrases or clauses starting with the expressions like "while...", "at the time of ..." and "when ...", the language speakers are found to use reduplicated structures with more acceptability in case of communication. This semantic feature is restricted to the reduplicated verb forms. Above examples number 7,8 and 9 convey the semantic feature simultaneity of action.

5. Repetition/Continuation

The reduplicated expressive that are imitative of sounds, are often found to convey 'repetition' or 'continuation' of the sound or 'plurality' of the sound. That is, a sense of repeated or continued 
action is conveyed by the expressive imitating the sounds. Usually, as such a repeated action is not followed by any resultant effect. (Dattamajumdar 2001:42) This semantic feature is conveyed in the above examples number $-13,14,15,16,17,18$ and19.

\title{
NOTES:
}

1. The suffix /-p ב / for imperfective participle is used after vowel ending verb forms whereas /-bJ/ is used after consonant ending verb forms.

\section{Acknowledgements}

I am extremely thankful to Prof. Ashoke Kumar Dutta and Shri Amlan Dutta of Bom-Bom Charitable Trust for initiating me in the present study and helping me to collect the data. I am also thankful to Prof. Krishna Bhattacharya for her insightful comments in dealing with the language data.

\section{List of abbreviations used}

\author{
acc. $=$ accusative \\ ag. $=$ agentive (suffix) \\ conj. $=$ conjunctive \\ det. $=$ determiner \\ expr. $=$ expressive \\ gen.=genitive case \\ imp. $=$ imperative $\operatorname{mood}$ \\ impf. parti. $=$ imperfective participle \\ inter. $=$ interrogative \\ loc. $=$ locative case \\ neg. $=$ negative \\ past $=$ simple past \\ past pf. $=$ past perfect \\ pl. = plural number \\ pr. $=$ simple present tense \\ pr. cont. $=$ present continuous tense \\ pr.pf. =present perfect tense \\ sg. = singular number \\ $1^{\text {st }}=$ first person \\ $2^{\text {nd }}=$ second person \\ $3^{\text {rd }}=$ third person
}




\section{REFERENCES}

Abbi,A.(1992). Reduplication in South Asian Languages- An Areal, Typological and Historical Study. New Delhi: Allied Publishers.

Bangroo,V. and Stronski,K. (2002). 'Malana:Shangrila in the Himalayas' IGNCA. www. Kanashi Language Wikipedia. (Retrieved on $25^{\text {th }}$ January 2013)

Dattamajumdar, S. (2001). A Contrastive Study of the Reduplicated Structures in Asamiya, Bangla and Odia. Kolkata: Subarnarekha.

Lewis, M. P. (ed.), (2009). 'Kanashi, a language of India' In: Ethnologue: Languages of the World, $16^{\text {th }}$ (edn.), Dallas, Tex.: SIL International, http://www.ethnologue.com/show_language.asp?code=xns (Retrieved on $25^{\text {th }}$ January 2013)

Moseley, Christopher (ed.). (2010). Atlas of the World's Languages in Danger, 3rd edn. Paris, UNESCO Publishing. Online version: http:// www.unesco.org/ culture/en/ endangeredlanguages/atlas (Retrieved on $8^{\text {th }}$,May 2013).

Sharma,D.D. (1989).Tribal Languages of Himachal Pradesh. Pt.:1.Delhi: Motilal Publications. http://archive.ethnologue.com (Retrieved on $20^{\text {th }}$ March 2013) 